\title{
Applying Best-Worst Scaling to Determine Architecture Students' Prioritisation of Studio Attributes
}

\author{
Chih Siong Wong \\ Department of Architecture \\ School of Built Environment \\ University College of Technology Sarawak \\ *Corresponding author: cswongdream@gmail.com
}

\begin{abstract}
Architecture students spend a considerable amount of their credit hours inside the studio, working on their design projects in a bid to practice all the skills and knowledge acquired throughout their studies. The dual nature of the studio is grounded in its uniqueness as both a physical setting and a pedagogy. These two elements have resulted in the studio becoming a crucial component in architectural education. Despite the studio being a critical physical set up for gaining architectural knowledge, there has arisen a deficiency in the empirical research data, specifically in terms of a person-environment congruence. Therefore, this study aims to determine the end-users' priorities. The main objective is providing insight into establishing the studio attributes that are prioritised by architectural students. The finding is a useful reference point when planning and designing a student-centred studio environment. The Best-Worst Scaling (BWS) approach forms the basis of this quantitative research through the use of a questionnaire survey. A case study was conducted at University College of Technology Sarawak (UCTS). The respondents were one hundred and sixty-eight undergraduate students of architecture programme. The ranking order of sixteen studio attributes arose from the results compiled from the BWS analysis. The aforementioned attributes can be scrutinised depending on their relative levels of significance. This study appropriately determines the ranking and relative importance of sixteen studio attributes in a straightforward graphical presentation of an environmental quality profile. The application of BWS is proven as a viable approach to determine students' prioritisation of studio attributes based on their perception.
\end{abstract}

Keywords: Architecture Education, Best-Worst Scaling, Environmental Quality Profile, Person-environment Congruence, Studio, Studio Attributes.

\section{Introduction}

Architecture programme involves a multitude of ways to deliver architectural design from different perspectives. Much of architectural education revolves around the studio. This provides a fertile environment in which architecture students can develop their vital design skills and critical thinking. There is no doubt that the studio is at the centre of the architecture program. Every subject is taught relative to the studio. It can be regarded as both an actual tangible space and a method of instruction (MAPSM, 2013). Studios is thus a physical setting where future architects are instructed about the crucial facets of design (Ledewitz, 1985). However, there has been very little empirical research conducted on the studio as a psychical learning environment (Muniandy, Khan, \& Ahmad, 2015; Obeidat \& Al-Share, 2012). Regrettably, there is very little 
understanding as to the role of the studio as a place of gathering for students where they can consult and interact with one another. As a matter of fact, most studio studies are usually conducted outside of Malaysia. What we do know about this subject in the context of Malaysia is frequently confined to the studies of indoor environmental quality (Che-Ani, Tawil, Musa, Yahaya, \& Tahir, 2012; Mirrahimi, Ibrahim, \& Surat, 2012; Nasir et al., 2011).

This study aims to determine the architecture students' priorities of the studio environment. As postulated by Cassidy (2013), space design shall be change from merely creating a geometric design to considering the user's experience and behaviour within the physical space. The studio's emphasis on the relationship between the person and his environment makes it imperative to research the influence of a student's inclinations on their perceptions of the quality of a space. Users of the space must provide personal feedback through methodical enquires before a studio can be designed and built to accommodate their needs. A better understanding of the studio can be acquired through an examination of how architecture students view the environment which they use. The main objective of this study is thus focusing on the establishment of the studio attributes that are prioritised by architectural students. The way these students prioritise the various attributes of the studio should be carefully analysed to find out the weight of each in relation to each other. The analysis provides excellent insight into the studio environment as seen from the eyes of the students. By getting their perspective, it is possible to foster better learning conditions.

\section{Literature Review}

\section{Studio as Learning Environment}

According to Stamps (1994), the architecture students may use up almost one third to one half of their entire university study time within a studio environment. Given this high proportion of utilisation, it should be clear just how important it is to strive to optimise the benefits of the studio to their perennial occupants. This may seem like an easy task, but it is a difficult challenge because each student has distinct requirements that have to be considered. When trying to determine which studio features should be included to address learning requirements, it is crucial to know the difference between the studio and the traditional classroom (Brandt et al., 2013). After this, the focus can shift to the multiple factors that come together to attract students to the studio environment.

Teaching in a studio has been labelled as a practicum in the sense that this is a learning hub built to help architecture students discover the intricacies of design (Kvan \& Jia, 2005; Schön, 1984, 1985, 1987). The method employed relies a lot on learning through experience and exploration using Computer-aided design (CAD) software (Botchway, 2016; Ma \& Zhu, 2014). Students learn through active creation instead of being confined to learning theories from a textbook. When architecture students experience dealing with real-world issues and having to solve these in the studio, they can come up with various solutions unencumbered by the diversions present in the field. In other words, the studio can be the link between the theories of the classroom and the practicalities of the real world so they will be ready to deal with anything when it is time to embark on their careers (Teymur, 1992). The studio has a dual role in the education of architecture students (MAPSM, 2013). It is the primary training ground in which studio instructors can discuss design approaches and let students apply these lessons 
(Bashier, 2014). It is also a physical space where the students can freely discuss their ideas and get peer feedback. This can expand their horizons and show them possibilities that they might not have considered otherwise. It is clear that the social aspect of learning in a studio environment is vital to the student experience. Although students may be caught up in their own individual projects at their own workspace (Ivanovic, 2014) and seem disinterested in their surroundings, the casual interactions they can have in studios will serve them well (Aderonmu, Alagbe, Opoko, Oluwatayo, \& Alalade, 2015).

The vast majority of the architecture programme requires studio hours with instructor guidance. Still, students can go beyond their scheduled studio hours and utilise the studio space for their design projects (Abdullah, Beh, Tahir, Ani, \& Tawil, 2011; Bell, 2014; Ibrahim \& Utaberta, 2012; Pektas, 2012). Some of these projects are assigned individually while others are assigned to groups so that there are chances to exchange ideas. Therefore, the studio should be equipped with both personal and group workspace as according to Lembaga Arkitek Malaysia (LAM) (MAPSM, 2013). The studio is in fact a space in which to learn, work, sleep and live (King, Daunis, Tami, \& Scullin, 2017; Kolko, 2012; Lueth, 2008). Since students spend quite some time in studio interactions including consultations, critiques, and so forth, so the studio space design shall be conducive to establish a place attachment for their social and learning requirements (Franz, 1990; Ochsner, 2000; Scupelli \& Hanington, 2016; Tumusiime, 2013; Wang, 2010; Wendler \& Rogers, 1995).

\section{Design Challenge of Studio}

Research conducted in the past has concluded that people tend to behave well when they are in an elegantly designed place (Halpern, 2014; Walmsley \& Lewis, 2014). Indeed, the way that the environment has been set up is a significant influence on behaviour. All of these point out the importance of having empirical data to support the design of the studio. Systematic inquiries must be posed in relation to the students and their environment (Strange \& Banning, 2001, 2015). They should be asked how the studio can provide the ideal environment for their studies. Anything that induces stress should be removed, while features that can encourage growth should be included in the design. In other words, a supportive learning environment is essential to increase students' efficiency and productivity which in line with previous findings (HaverinenShaughnessy, Shaughnessy, Cole, Toyinbo, \& Moschandreas, 2015; Lee et al., 2012; Marchand, Nardi, Reynolds, \& Pamoukov, 2014).

It is crucial to obtain feedback from the students and act on what they say while designing the studio (Sanoff, 2016). This is a deceptively complex undertaking given the varying and sometimes divergent ideas of the students. All of them will have their own interpretation of the physical aspects of the design, and that will paint a picture of their connection with the studio (Kamrani \& Behzadfar, 2016). Besides, their interpretation might be influenced by generational differences. Students these days are the millennial generation who has grown up surrounded by all types of digital technologies (Palfrey \& Gasser, 2013; Schulmeister, 2015). They are considered naturally proficient with all sort of digital gadgets (Ahn \& Jung, 2016; Gikas \& Grant, 2013; Livingston, 2004) and live online all the time (Gu, Zhu, \& Guo, 2013; Kivunja, 2014; Much, Wagener, Breitkreutz, \& Hellenbrand, 2014). Their space perceptions are hence having significant consideration concerning digital-related technologies. Designers must understand how different users make their interpretations to make the best choices for their designs. A studio can only provide optimum results if it has the 
elements that suit student needs (Strange \& Banning, 2015). This requires a great deal of study and analysis. The process may be simplified by breaking things down to the component parts such as attributes. These parts should be able to be listed, ranked, and scrutinised (Craik, 2013; Khattab, 1993; Rapoport, 1989, 2016). After this, a suitable environmental quality profile can be developed to organise and summarise data into a more digestible form.

\section{Studio Attributes}

Wong and Jusan (2017) postulate that the studio environment can be translated into attributes based on the perceptions of architecture students. They manage to identify sixteen studio attributes in their qualitative study, using the Means-End Chain (MEC) research approach. These studio attributes include lighting, ventilation, air conditioning, group work area, private workspace, pantry, leisure area, sleeping area, mini library, table and chair, lockable cabinet, pot plant, high-speed $\mathrm{Wi}-\mathrm{Fi}$, plotter, high spec computer, and power socket. All sixteen studio attributes offer the necessary support to satisfy the various educational needs of undergraduate architecture students. These attributes play a vital role to increase their study efficiency and help to achieve better productivity in order to achieve good outcomes. Besides, Wong and Jusan (2017) have also identified six motivational values that determine the elicitation of sixteen studio attributes. These values consist of achievement, security, self-direction, hedonism, conformity, and power.

The findings of Wong and Jusan (2017) sheds new light on architecture students' preferred studio attributes. However, their emphasis is more on the motivational values and beneficial consequences of the sixteen studio attributes. Their MEC investigation method treats the sixteen studio attributes separately during the interview phase. Consequently, their respondents might not be able to compare each of the studio attributes. Therefore, the way students choose and prioritise these sixteen studio attributes remain unanswered, which could pave the way for further investigation. Interestingly, Best-Worst Scaling (BWS) is an effective method to prioritise studio attributes and subsequently generate an environmental quality profile.

\section{Best-Worst Scaling Method to Prioritise Studio Attributes}

The Best-Worst Scaling (BWS) method was first developed in 1987 by Louviere and later published in 1991 (Jordan J Louviere \& Woodworth, 1991). The BWS refers to a survey technique that is utilised in the assessment of individuals' preferences and priorities: which essentially covers what respondents consider the best and worst amongst a given group of items. In terms of principles of data analysis, the best-worst choice is akin to what you would find in a discrete choice experiment (A. A. Marley \& Flynn, 2012). Both share a similar characteristic of following the Random Utility Theory (RUT) as their theoretical guideline. In RUT, the assumption that people are prone to making mistakes is made. However, if they happen to make a selection repeatedly, the frequency of their choices will be an indication of how much they value their options. Therefore, the rate in which you choose $\mathrm{X}$ over $\mathrm{Y}$ is a strong indication of your preference of X to Y. Thurstone (1994) suggested the use of RUT, and this motivated the development of the paired comparison technique so that respondents are tasked with choosing the "best" when asked to pick between two items. By presenting these choices to an individual, it is intended to uncover their relative preferences 
amongst given options (Flynn \& Marley, 2014; J.J. Louviere, Flynn, \& Marley, 2015; A. A. Marley \& Flynn, 2012; A. A. J. Marley, 2008).

BWS technically replicates the cognitive process through which individuals identify both objects in terms of their best and worst attribute from available selection sets (J.J. Louviere et al., 2015; Jordan J Louviere \& Woodworth, 1991). An ordinal standing of the objects is produced using the BWS for each individual. Additionally, an interval scale of the object segment or sample aggregate response is also produced. The technique enables respondents to measure importance through several comparisons as they are allowed to like an item as well as dislike others. Since one is only allowed to choose the most and least appealing option, the element of bias is eliminated from the rating scale. The BWS technique assumes that there exist inequalities amongst selections. As a result, there is relative importance within a cohort of choices. BWS essentially enables researchers to quantify the relative importance of an item within a group of other considered items (Flynn \& Marley, 2014; J.J. Louviere et al., 2015). Two main advantages come with using the BWS technique (J.J. Louviere et al., 2015). Firstly, because it is less cognitively tasking to choose the extremes of scales than to rank objects concurrently, the task can be easily completed by respondents. Secondly, the data collected is sufficient and informative enough for the researcher to calculate and compare individual-level scales accurately.

\section{Methodology}

\section{Questionnaire Design}

The questionnaire design for this research adopted the BWS object case method to compute and rank the relative importance of various studio attributes, which could influence the extent of studio usage. A similar method was conducted previously in many areas concerning the built environment (Balbontin, de Dios Ortúzar, \& Swait, 2014, 2015; Larranaga, Arellana, Rizzi, Strambi, \& Cybis, 2019; Oestreich, Lemes, Torres, Pereira, \& Ruiz-Padillo, 2019; Teffo, Earl, \& Zuidgeest, 2019; Weidmann \& Kelly, 2011). Therefore, A two-section questionnaire was devised. This questionnaire had an introduction explaining that its function was to determine the most significant attributes of studio environments. The initial section of the survey featured three questions about classification: study year, gender, and age. The following part of the questionnaire consisted of twenty selection sets centre on aforementioned sixteen studio attributes as highlighted by Wong and Jusan (2017), which measured the significance respondents ascribed to certain aspects of the studio using the BWS strategy. Figure 1 displays a BWS selection set, as featured in the survey. Respondents were given the option to choose the best and worst choice among the attributes shown in the sets.

\begin{tabular}{|c|c|c|}
\hline Studio Attribute & Best & Worst \\
\hline Lighting & o & 0 \\
\hline Ventilation & ○ & o \\
\hline High-speed Wi-Fi & o & o \\
\hline iv. Group work area & o & o \\
\hline
\end{tabular}

Figure 1: Screenshot Example of a BWS Selection Set 
The twenty choice sets for sixteen studio attributes featured in the survey were modelled on a Balanced Incomplete Block Design (BIBD) suggested by Louviere, Flynn, and Marley (2015). This study used a Balanced Incomplete Block Design of $b=20, r=5$, $\mathrm{k}=4$, and $\lambda=1$. In the twenty selection sets (b), all studio attributes appeared five times $(\mathrm{r})$ on the available selection sets. Every selection set had four studio attributes (k), and every studio attribute was compared one time to every other studio attribute $(\lambda)$.

\section{Sampling Strategy and Questionnaire Administration}

This study utilised purposive sampling, which is a non-probability sampling method. This strategy aimed to sample suitable respondents in a fast and systematic way without worrying about data proportions (Bryman \& Bell, 2015; Etikan, Musa, \& Alkassim, 2016). This sampling method was based on three primary considerations, namely suitability, availability, and accessibility. The targeted respondent group was deliberately selected to be involved in this study because they were knowledgeable about the studio space. Also, the chosen group was in the researcher's working institution, so every respondent was readily accessible and happy to take part in the research. As well as this, the researcher had quick and easy access to every targeted respondent. Consequently, the researcher could oversee and perform the study in a cost-effective and timely way. These practical considerations allowed the collection of meaningful data within a reasonable timeframe.

Overall, one hundred and sixty-eight students involved in the survey were from the Architecture Department, School of Built Environment at University College of Technology Sarawak (UCTS). Each respondent was studying their first architecture degree. The choice to include only undergraduate students from the same programme was because they had a similar mentality and educational background. Every respondent was handed a questionnaire in their studio lessons, which they had to complete instantly. Therefore, all the questionnaires were collected straight away after completion. On average, these questionnaires took roughly a quarter of an hour to complete.

\section{BWS Data Analysis}

The BWS survey gathered data regarding the worst and best selections for each studio attribute. The collected data was inputted into the IBM SPSS Statistic Twenty for BWS assessment. In this study, the BWS assessment focused on two primary aspects of studio attributes in terms of their ranking and relative importance. Therefore, the total number of best and worst counts for each attribute was determined to gauge the degree of significance for all the sixteen studio attributes. The total quantity of occasions a studio attribute was selected as the worst choice was subtracted from the total amount of times a studio attribute was chosen as the best choice for every respondent. As a result, the level of importance for all sixteen studio attributes can be calculated. The level of importance was governed by the frequency each studio attributes appeared in the selection sets. Since every individual studio attribute only appeared on five occasions in the selection tasks, the level of importance ought to be within minus five to plus five for every studio attribute. Values that fall outside the predefined occurrence range were regarded as errors. The level of importance for each of the studio attributes was converted into a Standard Score using a formula as follows:

Standard Score $=\frac{\text { Count }(\text { Best })-\text { Count }(\text { Worst })}{5 n}$ 
Where:

- $\quad$ Count $($ Best $)=$ the frequency of a studio attribute is chosen as 'Best' choice

- $\quad$ Count (Worst) $=$ the frequency of a studio attribute is chosen as 'Worst' choice

- $5=$ the frequency of occurrences of a studio attribute in all selection sets

- $\mathrm{n}=$ the total number of respondents

The Standard Scores were only able to determine the ranking order of the sixteen studio attributes. Nonetheless, Standard Scores along was not informative enough because the values did not offer any data on the relative significance of the studio attributes. Therefore, an effective method to assess the relative importance of the studio attributes was to calculate Square Root of Best to Worst counts (SQRT B/W) (Adamsen, RundleThiele, \& Whitty, 2013; Louviere et al., 2015).

$\operatorname{SQRT}(B / W)$ Score $=\sqrt{\frac{\text { Count (Best) }}{\text { Count (Worst) }}}$

Where:

- $\quad$ Count $($ Best $)=$ the frequency of a studio attribute is chosen as 'Best' choice

- Count (Worst) $=$ the frequency of a studio attribute is chosen as 'Worst' choice

These SQRT (B/W) Scores came with ratio values were standardised based on the least significant element of the sixteen studio attributes assessed. The least significant attribute was scaled to one for easy calculation. These Standardised SQRT (B/W) Scores were referred to as Relative Importance Scores in this study. The Relative Importance Scores revealed the relative importance of all the sixteen studio attributes for a simple and straightforward comparison.

\section{Findings}

\section{Characteristics of Respondents}

Table 1 illustrates the characteristics of one hundred and sixty-eight respondents involved in this study. The respondents consisted of seventy-four females and ninetyfour males with an average age of 21 years old. Sixty-four respondents were from Year One. Year Two and Year Three comprised of fifty-eight and forty-six respondents, respectively.

Table 1 Characteristics of The Respondents

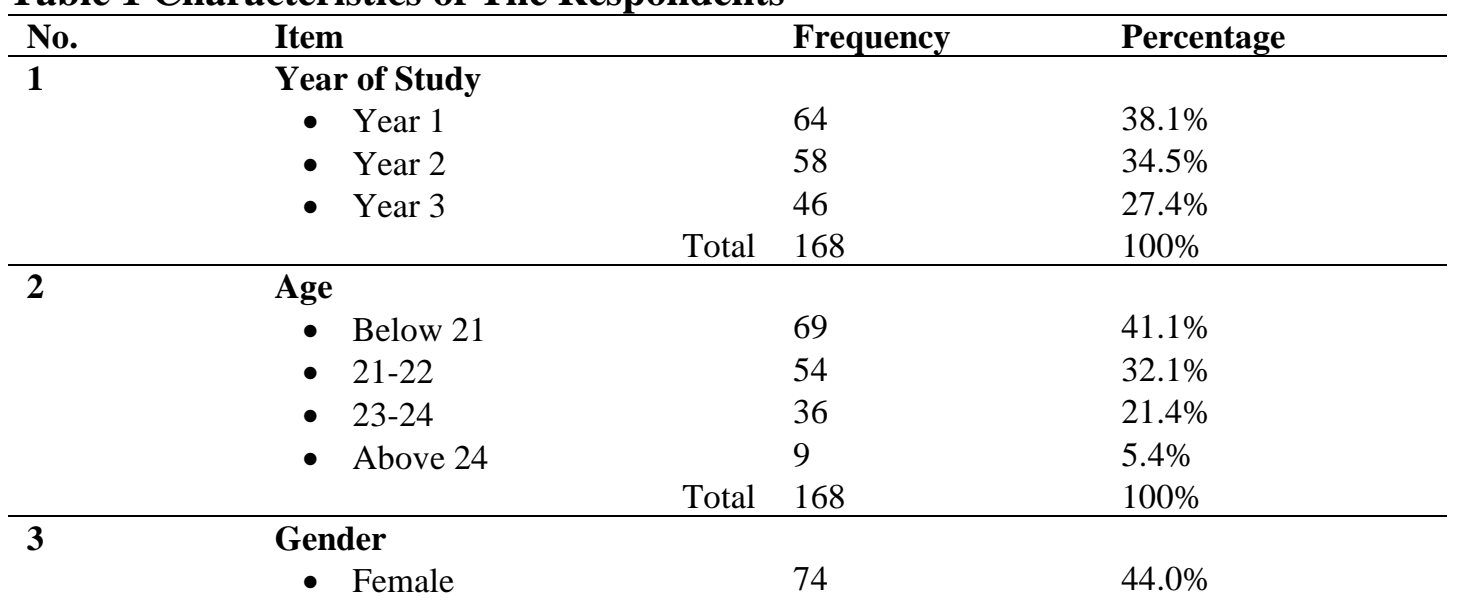




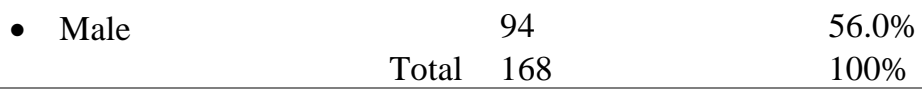

Source: Author

\section{Ranking and Relative Importance of Studio Attributes}

Table 2 shows the summary statistics of the BWS of sixteen studio attributes derived from the BSW survey. Subsequently, the clustered bar charts as shown in Figure 2 and 3 , have been generated to portray the ranking and relative importance of studio attributes.

Table 2 Summary Statistics of Best-Worst Scaling (BWS)

\begin{tabular}{lllll}
\hline Rank & Studio Attributes & Standard Score & SQRT $(\mathbf{B} / \mathbf{W})$ & Relative Importance Score \\
\hline 1 & High-speed Wi-Fi & 0.419 & 1.94 & 13.26 \\
2 & Air conditioning & 0.387 & 1.84 & 12.62 \\
3 & Private workspace & 0.220 & 1.45 & 9.92 \\
4 & Power socket & 0.194 & 1.31 & 8.93 \\
5 & Table and Chair & 0.176 & 1.28 & 8.73 \\
6 & High spec computer & 0.144 & 1.22 & 8.32 \\
7 & Lighting & 0.143 & 1.19 & 8.14 \\
8 & Ventilation & 0.045 & 0.92 & 6.28 \\
9 & Group work area & -0.051 & 0.91 & 6.22 \\
10 & Sleeping area & -0.096 & 0.79 & 5.38 \\
11 & Plotter & -0.110 & 0.66 & 4.50 \\
12 & Lockable cabinet & -0.117 & 0.53 & 3.62 \\
13 & Leisure area & -0.229 & 0.47 & 3.18 \\
14 & Pantry & -0.268 & 0.46 & 3.15 \\
15 & Mini library & -0.362 & 0.32 & 2.20 \\
16 & Pot plant & -0.496 & 0.15 & 1.00 \\
\hline
\end{tabular}

Source: Author

Table 2 and Figure 2 show two forms of standard scores, the negative score, and the positive score. A positive value indicates that an attribute has been chosen more often as the best choice than a worse choice. A negative value of an attribute shows that it has been selected as the worst choice more often than as the best choice. For easy understanding, the attributes have been carefully sorted and arranged from the most important to the least important attribute. The attribute with the highest score is considered to be of great importance to respondents, while the attribute with the lowest score is deemed to be of least importance to the respondents. 


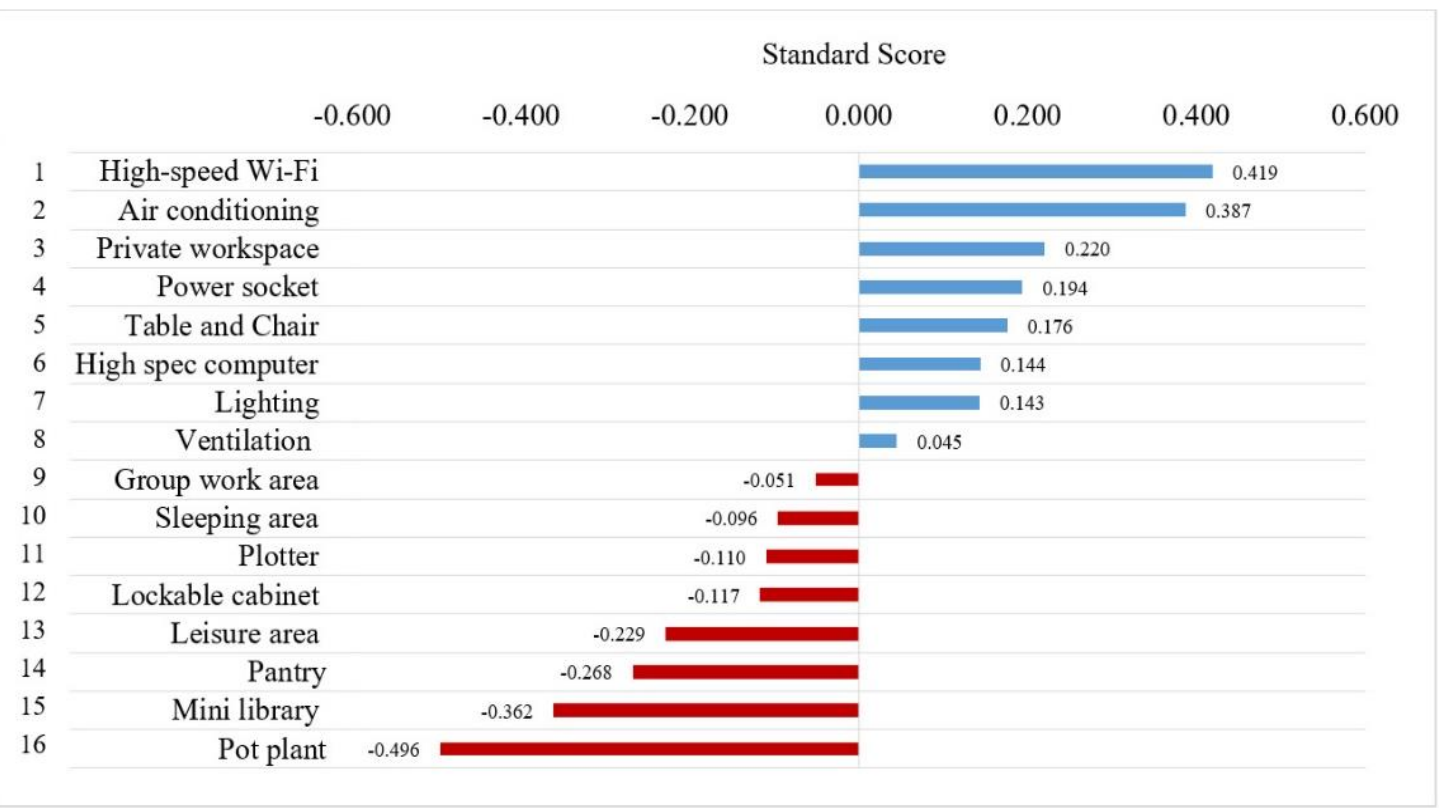

Figure 2: Ranking of Studio Attributes

Source: Author

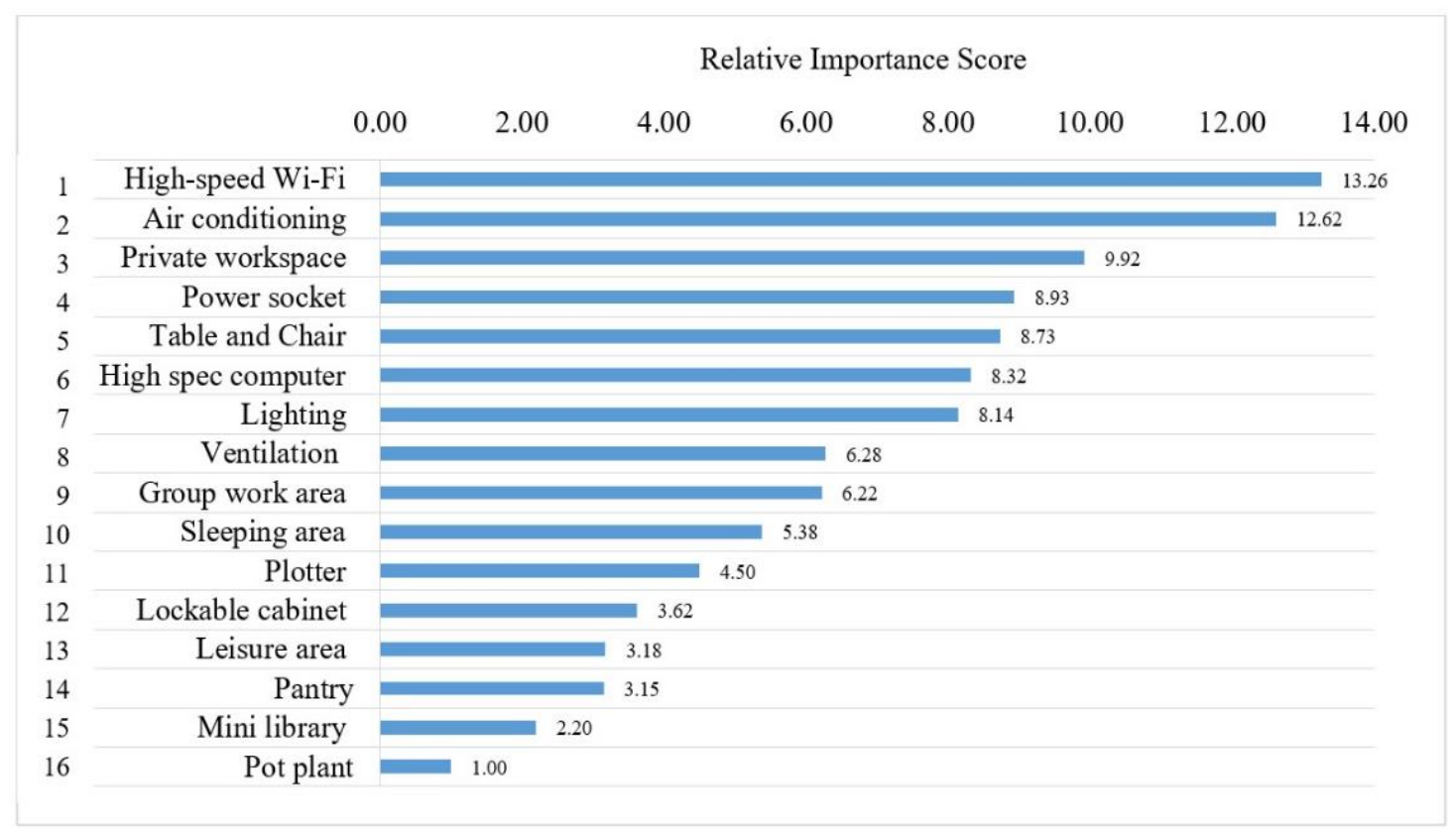

Figure 3: Relative Importance of Studio Attributes

Source: Author

Eight of the sixteen studio attributes are considered to be of more importance to respondents since they have positive standard scores. In an architecture studio, highspeed Wi-Fi is the most preferred attribute, with a standard score of 0.419. Air conditioning comes second with a standard score of 0.387 . Thus, the first attribute is 1.05 more than the second attribute. The second and third attributes have the largest standard scores gap. The findings clearly show that high-speed Wi-Fi and air conditioning are unique from the rest of the attributes. Out of the sixteen studio attributes, the two are considered to be of utmost importance. Private workspace with a standard 
score of 0.220 takes third place, while the power socket with a standard score of 0.194 takes fourth place. The table and chair take fifth place with a standard score of 0.176. Private workspace is 1.11 more times important than power sockets. A closer look at the results indicates that the fourth and fifth studio attributes have equal relative importance. The sixth and seventh attributes, high spec computer, and lighting have a similar significance as they have a standard score of 0.144 and 0.143 , respectively. Ventilation takes the last place of the eight most preferred attributes in the list, with a standard score of 0.045 .

The rest of the attributes have negative standard scores. They are the least favourite attributes in the sample. They may not be appealing as the eight attributes ranking on the top, but that does not make them unimportant. The group work area has taken the ninth place of the list with a standard score of -0.051 . Ventilation, which takes the eighth position, has a relative alike importance pattern with a group work area. A similar trend is not present from the tenth to twelfth studio attributes. The sleeping area takes the tenth position with a standard score of -0.096 , while plotter takes the 11th position with a standard score of -0.110 . A lockable cabinet takes the twelfth position with a standard score of -0.117 . The thirteenth attribute, leisure area, has a standard score of -0.229 , followed by the pantry, with a standard score of -0.268 . The two attributes have a relative alike pattern. The mini library takes the fifteenth position, with a standard score of -0.362 . The least essential studio attribute is a pot plant that sits with a standard score of 0.496 .

\section{Discussion}

\section{High-speed Wi-Fi}

Architecture students rate high-speed Wi-Fi as their top studio attribute. All of the students in this group are millennials, and everyone knows that this particular generation likes digital technology more than most other generations (Palfrey \& Gasser, 2013). They are very knowledgeable when it comes to digital technologies, communication and media (Schulmeister, 2015). As a result, you can usually find them glued to their mobile devices (Ahn \& Jung, 2016). They cannot stand to part with them. If it were up to them, they would live on their devices 24/7. High-speed Wi-Fi makes it possible for millennials to remain connected with the world consistently. Not only does it keep them connected to the world, but it also keeps them entertained. It also helps them to research and learn about everything around them with just a few clicks of a mouse. Digital technology has made it so easy for millennials to learn because they are wired more than most of the generations that have come before them (Gu, Zhu, \& Guo, 2013; Kivunja, 2014; Much, Wagener, Breitkreutz, \& Hellenbrand, 2014). Therefore, students consider $\mathrm{Wi}-\mathrm{Fi}$ as their top priority comes as no surprise in a studio context.

\section{Air Conditioning}

Based on the result, air conditioning is the second top priority in the studio for architecture students. In a hot and humid climate country like Malaysia, maintaining thermal comfort indoors is always essential. Besides, the younger generation maybe does not have a high tolerance level when it comes to high temperature. Air conditioning keeps the indoors comfortable level no matter what the temperature may be outdoors. When students are relaxed and comfortable in the studio environment, their efficiency and productivity are greatly improved. This belief supports what was proven in other 
studies such as that of Lee et al. (2012), Marchand, Nardi, Reynolds, and Pamoukov (2014), \& Haverinen-Shaughnessy, Shaughnessy, Cole, Toyinbo, \& Moschandreas (2015).

\section{Private Workspace}

Next on the students' priority list is having a private workspace. Students prize having their own workspace that they do not have to share with anyone else (Ivanovic, 2014). Not only can they use the space whenever they want to, but they can also personalise it according to their unique wants and needs. It helps them to establish a place attachment and gives them a place of belonging (Scupelli \& Hanington, 2016). A private workspace helps the process of learning because it provides security and comfort for students. When they have a quiet place where they can focus, they can truly work within their design world. Yes, uninterrupted solitude is needed to make the design process a successful one. If a design issue presents itself, students have the space to work, explore, create and find a solution. This finding is in line with studio requirements imposed by LAM where it is mandatory for architecture school to provide each student with a dedicated workspace in a studio environment (MAPSM, 2013).

\section{Power Socket}

Millennials have tons of things such as tablets, smartphones, laptops and other digital gadgets at their disposal (Gikas \& Grant, 2013). These gadgets have become this generation's Swiss Army Knife as sorts (Livingston, 2004). They are the tools that they need to be successful online. They help them get the information that is necessary to make their designs presentable and much better. Thus, it should not be surprising that they highly prize both table and chair (at fifth) and power socket (at fourth). Power sockets make it possible for them to connect their devices in the studio. There are enough sockets throughout the studio, which means students can plug in and constantly have power and not be interrupted when designing. This gives them the reassurance that they can be productive and finish what needs to be done.

\section{Table and Chair}

Each student needs a good table and chair to draw in the studio. These things are just as important as having a private workspace. Without these things, it is just as useless as owning a gun without any bullets. A Chinese saying makes a point that one must have the right working tools in order to get the job done correctly. In this example, the tools are the table and chairs. The job would be drawing or design. Architectural students need an adjustable drafting table that can be configured per user's needs. They also need a chair that is suitable for their height. Students want and need ergonomic tables and chairs in their private workspaces to work on their design project. It allows them to be comfortable and productive.

\section{High Spec Computer}

Students also need an excellent high spec computer, which is highly prized for design presentation and exploration. Computer-aided design (CAD) software for twodimensional drawings and three-dimensional modelling is not very uncommon in the architectural world of today (Botchway, 2016; Ma \& Zhu, 2014). Students need these types of software packages for their designs to be good ones. The higher the specifications and configurations, the smoother the design presentation production. It is 
much easier and quicker to complete design tasks such as rendering and threedimensional modelling with a high spec computer. Students do not have to spend as much time on their projects when these types of computers are used. Yes, they may cost more in the long run, which means not everyone can afford them. This is why students fancy a studio readily equipped with high spec computers by architecture school.

\section{Lighting}

Just like high spec computers, students also value good lighting in the studio. They need visual clarity within a range of three hundred to four hundred lux of illumination for studio design tasks (Malaysia, 2014). The right lighting can make or break a design project. Visual comfort in the studio is essential in the form of either artificial or natural light. The right type of lighting also ensures safety in the workspace. The wrong kind of lighting could cause eyestrain, which leads to blurred vision and headaches (Musa, Abdullah, Che-Ani, Tawil, \& Tahir, 2012). Obviously, students do not want to end up with poor vision as a result of inadequate lighting in the studio.

\section{Ventilation}

Proper ventilation is also crucial to architectural students. This is because they want the right temperature setting and good indoor air quality within the studio environment. A quality ventilation system removes pollutants and bad odours. There is also a concern when air-conditioning is not present. UCTS turns off the air conditioning after office hours, and the ventilation system is the only way to keep the studio environment comfortable during these hours. Usually, windows must be opened to get good airflow in the studio. Basically, students want their workspace to be comfortable and free of pollutants. This helps them to be more productive.

\section{Group Work Area}

Students do not consider group work area as necessary as their private workspaces. Students have more control over their private spaces, which are permanent. On the other hand, students perceive the group work area as a temporary working space shared by other studio mates. This does not mean that they overlook the importance of a functional group work area in the studio. Students place a lesser amount of priority on group work area than private workspace is mainly because they do not need the space frequently. However, LAM requires architecture school to provide group work area in the studio context (MAPSM, 2013). Students still need to use this space to work and learn together on specific group projects.

\section{Sleeping Area}

Architectural students are well known for working on their design projects during late hours at night. Working overnight in the studio is especially common, which means they might need a space for quick naps and rest breaks. Having and maintaining this type of space allows students to be productive and focused. Unfortunately, many of them have to sacrifice their sleep time to successfully meet their submission due date (King, Daunis, Tami, \& Scullin, 2017). Needing a space to relax and sleep is not their priority anymore, especially when submission deadlines loom on the horizon. Needless to say, many students choose to rest or nap in their private workspaces, so a sleeping area is not rated as high as the attributes mentioned above. However, it is still a good thing to have. 


\section{Plotter}

Students consider the plotter as a necessary studio attribute mostly because it makes printing tasks convenient for them. However, the plotter is usually not needed until a submission due date is around the corner. It is not something that is required as much as their tables, chairs, and private spaces. The absence of a plotter in the studio does not have a significant impact on students. Students can still use outside sources for their printing needs. All in all, consideration to have plotter in the studio relates directly to the quality of being convenient and time-saving, especially approaching the submission deadline.

\section{Lockable Cabinet}

Lockable cabinets are ideal places for students to store their personal belongings. Although this is a good thing to have, most students do not need them to produce their designs. They can just place their stuff at their private workspaces. The good thing is that most students trust their studio mates because they have worked with them for a long time. Besides, the studio has 24/7 closed-circuit television security. On the other hand, students still think that having a lockable cabinet is more important than having a pantry, leisure area, mini library, or potted plant in the studio. Keep in mind that none of these things is necessary for them to produce their drawings and designs. That is the reason why they are ranked low on the list.

\section{Leisure Area}

Having a leisure area is ranked fourth from the bottom, which means it is not that high of an attribute for most students. A leisure area could be a fun place for social interaction in the studio. However, students use the studio mainly for learning needs instead of leisure purposes. Besides, they can always enjoy their leisure activities at varieties of outdoor spots. Furthermore, working in the studio takes up a majority of their time, and this leaves little time to have fun and socialise.

\section{Pantry}

Students do not put pantry high up on the list. They can bring their own drinks and food to the studio. In UCTS context, students can always get something to drink and eat from vending machines without wasting valuable time trying to find food sources. Also, it is very convenient for students to purchase items from the local cafeteria, which is only a few steps away from the studio. Moreover, they can choose from various types of restaurants and coffee shops that are close to the campus. They have so many options that having a pantry in the studio is not a high priority.

\section{Mini Library}

The students who participated in this study are very knowledgeable about digital technology and the internet. The internet is their number one source of information, and they can get what they need within a few seconds and clicks. A mini library might have useful information, but students feel that the internet is much better for giving them what they need at their fingertips instantly. Thus, it should no surprise that students do not put much importance on having a mini library. Although it is a good thing to have, it is not a necessity for students. They view it as having a bonus or backup source or information and not one of priority. In reality, they can still work in the studio without having a mini library. 


\section{Pot Plant}

The pot plant is ranked the lowest on the list of attributes that students prefer in a studio environment. Students perhaps do not feel that pot plant is required to enhance productivity, efficiency, or even comfort. Unlike ventilation and air conditioning that keeps them relax and provides comfort, having a potted plant in the studio does neither of these things. It does nothing to help them reach their studio learning goals. Therefore, the priority level on the pot plant is undoubtedly diminished.

\section{Conclusion}

The BWS research model is an efficient approach to determining the studio attributes relative importance and rank order. Besides, BWS ensures that attributes of the studio can be graphically presented as simple as a clustered bar chart (Figure 2 and Figure 3). Such graphical form of a studio environmental quality profile can illustrate students' priorities and preferences. The ability of the environmental quality profile to organise and merge the extensive pool of knowledge in a clear, simple and meaningful way is one of its key advantages. It enables the users to convey their desired environmental quality through attributes prioritisation efficiently. Studio environmental quality profile has undoubtedly provided further insight into the relationship present between the studio and architectural students in terms of person-environment congruence. In actuality, the outcomes of the study indicate that the studio environmental quality profile is consistent with the educational requirements of architectural students. It is a representation of the collective picks made by architecture students regarding the different available studio alternatives. For one to design a supportive student environment, establishing a studio environmental quality profile is crucial. It may offer an excellent reference point to decision-makers and designers by giving them an understanding of the users' needs and preferences. They are thus able to reach sensible design conclusions using appropriately compiled data and outcomes. The studio environmental quality profile ultimately provides a crucial means of closing the gap in perception that exists between users and designers. Designers are usually able to deliver appropriate and quality studio designs after having a proper understanding of how studio spaces are utilised, perceived, and significant changes that need correction.

The sample study is restricted to undergraduate students pursuing architecture (LAM Part I) due to the constraint of time. Additional future research is proposed to involve postgraduate students undertaking architecture in LAM Part II of the study. By engaging students from the master postgraduate level, further insight may be gained into the attributes prioritised upon by students in the higher levels of study. Additionally, it gives the study a more extensive scope as it will be a compilation of all the students' perceptions across the entire architecture program. It would be interesting to compile and draw up the similarities and differences in discernments that are likely to arise between the different parties owing to the variations in the respondents' levels of study. Meanwhile, this study is mainly intended to dwell on the perception of architecture students towards studio attributes. Further research that may be organised in the future may choose to widen its scope to take into account the insights of a variety of stakeholders such as administrators, lectures and designers. Since environmental quality profiles can assess the preference and prioritisation, they can also be used when analysing or making comparisons between the profiles of a variety of parties. 
Environmental quality profiles are therefore determined not only agreements but also establish areas of conflict. These profiles prove to be essential during design formulations with the collected input from different stakeholders intended towards coming up with an improved studio design. It would be interesting to witness the emerging future trends, especially with increasing research geared towards redesigning architecture studios to support students' learning needs.

\section{Acknowledgement}

This study is supported by a research grant from the University College of Technology Sarawak (UCTS).

\section{References}

Abdullah, N. A. G., Beh, S. C., Tahir, M. M., Ani, A. I. C., \& Tawil, N. M. (2011). Architecture Design Studio Culture and Learning Spaces: A Holistic Approach to The Design and Planning of Learning Facilities. Procedia - Social and Behavioral Sciences, 15, 27-32.

Adamsen, J. M., Rundle-Thiele, S., \& Whitty, J. A. (2013). Best-Worst Scaling. Reflections on Presentation, Analysis, And Lessons Learnt from Case 3 BWS Experiments. Market \& Social Research, 21(1), 9-27.

Aderonmu, P. A., Alagbe, O., Opoko, P. A., Oluwatayo, A., \& Alalade, G. (2015). Deserted Studio and Culture in Architecture Schools: Issues of Policy And Implementation Strategies. Global Journal on Humanities \& Social Sciences, $1(1), 436-441$.

Ahn, J., \& Jung, Y. (2016). The Common Sense of Dependence on Smartphone: A Comparison Between Digital Natives and Digital Immigrants. New Media \& Society, 18(7), 1236-1256.

Balbontin, C., de Dios Ortúzar, J., \& Swait, J. D. (2014). Importance of Dwelling, Neighbourhood Attributes in Residential Location Modelling: Best Worst Scaling vs. Discrete Choice. Procedia-Social and Behavioral Sciences, 160, 92101.

Balbontin, C., de Dios Ortúzar, J., \& Swait, J. D. (2015). A Joint Best-Worst Scaling and Stated Choice Model Considering Observed and Unobserved Heterogeneity: An Application to Residential Location Choice. Journal of Choice Modelling, $16,1-14$

Bashier, F. (2014). Reflections on Architectural Design Education: The Return of Rationalism in The Studio. Frontiers of Architectural Research, 3(4), 424-430.

Bell, C. J. (2014). Space Unveiled: Invisible Cultures in The Design Studio. Taylor \& Francis.

Botchway, E. A. (2016). Software Application Employed in Architectural Design Education: The Case Of KNUST. Review of European Studies, 8(2), 30.

Brandt, C. B., Cennamo, K., Douglas, S., Vernon, M., Mcgrath, M., \& Reimer, Y. (2013). A Theoretical Framework for The Studio as A Learning Environment. International Journal of Technology and Design Education, 23(2), 329-348.

Bryman, A., \& Bell, E. (2015). Business Research Methods. Oxford University Press, USA. 
Cassidy, T. (2013). Environmental Psychology: Behaviour and Experience in Context. Psychology Press.

Che-Ani, A. I., Tawil, N. M., Musa, A. R., Yahaya, H., \& Tahir, M. M. (2012). The Architecture Studio of Universiti Kebangsaan Malaysia (UKM): Has the Indoor Environmental Quality Standard Been Achieved? Asian Social Science, 8(16), 174-183.

Craik, K. (2013). Perceiving Environmental Quality: Research and Applications. Springer US.

Etikan, I., Musa, S. A., \& Alkassim, R. S. (2016). Comparison of Convenience Sampling and Purposive Sampling. American Journal of Theoretical and Applied Statistics, 5(1), 1-4.

Flynn, T., \& Marley, A. (2014). Best-Worst Scaling: Theory and Methods. In A. D. Stephane Hess (Ed.), Handbook of Choice Modelling (Pp. 178-201): Edward Elgar Publishing.

Franz, J. M. (1990). Design Education in Architecture: A Psychosocial Analysis. Paper Presented at The Architectural Science and Design in Harmony. Joint Anzasca / ADTRA Conference, Sydney.

Gikas, J., \& Grant, M. M. (2013). Mobile Computing Devices in Higher Education: Student Perspectives on Learning with Cellphones, Smartphones \& Social Media. The Internet and Higher Education, 19, 18-26.

Gu, X., Zhu, Y., \& Guo, X. (2013). Meeting The" Digital Natives": Understanding the Acceptance of Technology in Classrooms. Journal of Educational Technology \& Society, 16(1), 392.

Halpern, D. (2014). Mental Health and The Built Environment: More Than Bricks and Mortar? Taylor \& Francis.

Haverinen-Shaughnessy, U., Shaughnessy, R. J., Cole, E. C., Toyinbo, O., \& Moschandreas, D. J. (2015). An Assessment of Indoor Environmental Quality in Schools and Its Association with Health and Performance. Building and Environment, 93, 35-40.

Ibrahim, N. L. N., \& Utaberta, N. (2012). Learning in Architecture Design Studio. Procedia - Social and Behavioral Sciences, 60, 30-35.

Ivanovic, G. W. (2014). People as Place-Making Coordinate: A Methodology for Visualising Personal Spaces. Frontiers of Architectural Research, 3(1), 36-43.

Kamrani, A., \& Behzadfar, M. (2016). Place Semantics Based on Lynch, Rapoport And Semiotics Viewpoints. European Online Journal of Natural and Social Sciences: Proceedings, 5(3 (S)), Pp. 82-90.

Khattab, O. (1993). Environmental Quality Assessment. Open House International, 18(4), 41-47.

King, E., Daunis, M., Tami, C., \& Scullin, M. K. (2017). Sleep in Studio Based Courses: Outcomes for Creativity Task Performance. Journal of Interior Design.

Kivunja, C. (2014). Theoretical Perspectives of How Digital Natives Learn. International Journal of Higher Education, 3(1), 94.

Kolko, J. (2012). Transformative Learning in The Design Studio. Interactions, 19(6), 82-83.

Kvan, T., \& Jia, Y. (2005). Students' Learning Styles and Their Correlation with Performance in Architectural Design Studio. Design Studies, 26(1), 19-34. 
Larranaga, A. M., Arellana, J., Rizzi, L. I., Strambi, O., \& Cybis, H. B. B. (2019). Using Best-Worst Scaling to Identify Barriers to Walkability: A Study of Porto Alegre, Brazil. Transportation, 46(6), 2347-2379.

Ledewitz, S. (1985). Models of Design in Studio Teaching. Journal of Architectural Education 38(2), 2-8.

Lee, M. C., Mui, K. W., Wong, L. T., Chan, W. Y., Lee, E. W. M., \& Cheung, C. T. (2012). Student Learning Performance and Indoor Environmental Quality (IEQ) In Air-Conditioned University Teaching Rooms. Building and Environment, 49, 238-244.

Livingston, A. (2004). Smartphones and Other Mobile Devices: The Swiss Army Knives of the 21st Century. Educause Quarterly, 27(2), 46-52.

Louviere, J. J., Flynn, T. N., \& Marley, A. A. J. (2015). Best-Worst Scaling: Theory, Methods and Applications. Cambridge University Press.

Louviere, J. J., \& Woodworth, G. G. (1991). Best-Worst Scaling: A Model for The Largest Difference Judgments. University of Alberta: Working Paper.

Lueth, P. L. O. (2008). The Architectural Design Studio as A Learning Environment: A Qualitative Exploration of Architecture Design Student Learning Experiences in Design Studios from First-Through Fourth-Year. (Ph.D.). Iowa State University, United States.

Ma, Y., \& Zhu, S. H. (2014). Architectural Design Using Autocad And Sketchup. Paper Presented at The Applied Mechanics and Materials.

Malaysia, S. (2014). MS 1525:2014. In Energy Efficiency and Use of Renewable Energy for Non-Residential Buildings - Code of Practice (Second Revision).

MAPSM. (2013). The Manual of Accreditation for Architecture Programme (S. I. Ariffin Ed.): Lembaga Arkitek Malaysia: Council of Architecture Accreditation and Education.

Marchand, G. C., Nardi, N. M., Reynolds, D., \& Pamoukov, S. (2014). The Impact of The Classroom Built Environment on Student Perceptions and Learning. Journal of Environmental Psychology, 40, 187-197.

Marley, A. A., \& Flynn, T. (2012). Best Worst Scaling: Theory and Practice. Handbook of Choice Modelling. Edward Elgar Publishing, Leeds (UK).

Marley, A. A. J. (2008). The Best-Worst Method for The Study of Preferences: Theory and Applications. International Journal of Psychology, 43, 168-168.

Mirrahimi, S., Ibrahim, N. L. N., \& Surat, M. (2012). An Analysis of Variation of Ceiling Height and Window Level for Studio Architecture in Malaysia. International Journal of Architectural and Environmental Engineering, 6(8), 708-712.

Much, K., Wagener, A. M., Breitkreutz, H. L., \& Hellenbrand, M. (2014). Working with The Millennial Generation: Challenges Facing 21st-Century Students from The Perspective of University Staff. Journal of College Counseling, 17(1), 37-47.

Muniandy, S., Khan, T. H., \& Ahmad, A. S. (2015). Evaluating the Physical Environment of Design Studios: A Case Study in Malaysian Private Architecture Schools. International Journal of Built Environment and Sustainability, 2(3).

Musa, A. R., Abdullah, N. A. G., Che-Ani, A. I., Tawil, N. M., \& Tahir, M. M. (2012). Indoor Environmental Quality for UKM Architecture Studio: An Analysis on Lighting Performance. Procedia - Social and Behavioral Sciences, 60, 318-324.

Nasir, A. R. M., Musa, A. R., Che-Ani, A. I., Utaberta, N., Abdullah, N. A. G., \& Tawil, N. M. (2011). Identification of Indoor Environmental Quality (IEQ) Parameter 
in Creating Conducive Learning Environment for Architecture Studio. Procedia Engineering, 20, 354-362.

Obeidat, A., \& Al-Share, R. (2012). Quality Learning Environments: Design-Studio Classroom. Asian Culture and History, 4(2), 165-174.

Ochsner, J. K. (2000). Behind the Mask: A Psychoanalytic Perspective on Interaction in The Design Studio. Journal of Architectural Education, 53(4), 194-206.

Oestreich, L., Lemes, J. A., Torres, T. B., Pereira, B. M., \& Ruiz-Padillo, A. (2019). Methodological Procedures For Studying Walkability In Cachoeira Do Sul Throught Best-Worst Scaling Technique. 2019, 9.

Palfrey, J. G., \& Gasser, U. (2013). Born Digital: Understanding the First Generation of Digital Natives. Basic Books.

Pektas, S. T. (2012). The Blended Design Studio: An Appraisal of New Delivery Modes in Design Education. Procedia - Social and Behavioral Sciences, 51, 692-697.

Rapoport, A. (1989). Environmental Quality and Environmental Quality Profiles. Paper Presented at The Quality in The Built Environment, Public and Private Responsibilities in Housing Design and Settlement Planning, Conference Proceedings, July 1989, Ed. N. Wilkinson, Open House International Association.

Rapoport, A. (2016). Human Aspects of Urban Form: Towards A Man-Environment Approach to Urban Form and Design. Elsevier Science.

Sanoff, H. (2016). Integrating Programming, Evaluation and Participation in Design (Routledge Revivals): A Theory Z Approach. Routledge.

Schön, D. A. (1984). The Architectural Studio as an Exemplar of Education for Reflection-In-Action. Journal of Architectural Education, 38, 2-9.

Schön, D. A. (1985). The Design Studio. London: RIBA Publication Ltd.

Schön, D. A. (1987). Educating The Reflective Practitioner. San Fransisco: Jossey-Bass Publishers.

Schulmeister, R. (2015). Deconstructing the Net Generation Thesis. Qwerty-Open and Interdisciplinary Journal of Technology, Culture and Education, 10(1), 69-103.

Scupelli, P., \& Hanington, B. (2016). Design Studio Desk and Shared Place Attachment: A Study on Ownership, Personalisation, and Agency. Paper Presented at The Design Research Society Conference Proceedings.

Stamps, A. E. (1994). Jungian Epistemological Balance: A Framework for Conceptualizing Architectural Education. Journal of Architectural Education, 48, 105-112.

Strange, C. C., \& Banning, J. H. (2001). Educating by Design: Creating Campus Learning Environments That Work. Jossey-Bass.

Strange, C. C., \& Banning, J. H. (2015). Designing for Learning: Creating Campus Environments for Student Success. John Wiley \& Sons.

Teffo, M., Earl, A., \& Zuidgeest, M. H. P. (2019). Understanding Public Transport Needs in Cape Town's Informal Settlements: A Best-Worst-Scaling Approach. Journal of the South African Institution of Civil Engineering, 61, 39-50.

Teymur, N. (1992). Architectural Education: Issues in Educational Practice and Policy. Question Press.

Thurstone, L. L. (1994). A Law of Comparative Judgment. Psychological Review, 101(2), 266.

Tumusiime, H. (2013). Learning in Architecture: Students' Perceptions of The Architecture Studio. In AAE Conference. 
Walmsley, D. J., \& Lewis, G. J. (2014). People and Environment: Behavioural Approaches in Human Geography. Taylor \& Francis.

Wang, T. (2010). A New Paradigm for Design Studio Education. International Journal of Art \& Design Education, 29(2), 173-183.

Weidmann, B., \& Kelly, J.-F. (2011). What Matters Most? Housing Preferences Across the Australian Population. In Grattan Institute Melbourne

Wendler, W. V., \& Rogers, J. S. (1995). The Design Life Space: Verbal Communication in The Architectural Design Studio. Journal of Architectural and Planning Research, 12(4), 319-336.

Wong, C. S., \& Jusan, M. B. M. (2017). Application of Means-End Chain Research Model to Explore Attributes of Architecture Studio. International Journal of Applied Engineering Research, 12(4), 498-508. 